\title{
Iconografía marginal: grafitos históricos en la casa nazarí de calle San Buenaventura, 2 (Gra- nada).
}

RESUMEN. Con estas breves líneas damos a conocer un interesante conjunto de grafitos históricos descubiertos en una casa morisca de Granada. La importancia de los mismos, no sólo se debe a la variedad temática que ofrecen (figuras humanas, motivos navales, motivos vegetales,...), sino que constituyen las primeras manifestaciones gliptográficas, procedentes de una antigua casa morisca. Se pretende con este trabajo, dar un primer paso en el estudio de estos grafitos históricos y de los que pudieran aparecer durante futuras restauraciones de otras casas moriscas de Granada.

Palabras clave: Grafitos históricos, casa morisca, motivos navales, Granada.

ABSTRACT. With these brief lines we show an interesting group of historic graffiti discovered in a morisca house from Granada. The importance isn't only about a variety thematic that we can observe (human figures, naval reasons, vegetal reasons,...) but these constitute the first glyptographic manifestations coming from an old morisca house. These are the aim of a study of these historics graffiti and also of all what could appear in future restorations of others moriscas houses in Granada.

Key words: Historics graffiti, morisca house, naval reasons, Granada.

Hemos podido comprobar como en nuestra ciudad, durante la rehabilitación de algunas antiguas viviendas, se realiza un feroz repicado de los distintos enlucidos que cubren los muros, dejando a la vista ya sea la piedra, el ladrillo o el tapial, sin que se efectúe previamente un detenido examen de aquellos. Ello ha supuesto la desaparición, con toda seguridad, de un sin fin de manifestaciones gliptográficas de todas las épocas, que desafortunadamente no hemos podido documentar. Unas manifestaciones populares que ofrecen información directa y de primera mano de un momento históri- co concreto, así como de las personas que las ejecutaron.

Sirva este trabajo de llamada ante la necesidad de establecer una estrecha colaboración, inexistente hasta ahora en nuestra tierra, entre arquitectos, arqueólogos y los que nos dedicamos al estudio de estos motivos, con el objeto de proteger, estudiar y difundir un patrimonio histórico y cultural digno de salvaguardar.

El trabajo que ofrecemos, es fruto del estudio que emprendimos sobre una serie de grafitos históricos aparecidos durante 
los trabajos arqueológicos y de rehabilitación, que el Laboratorio de Arqueología y Arquitectura de la Ciudad (LAAC), de la Escuela de Estudios Árabes de Granada (CSIC), realizaba en la casa morisca de la calle San Buenaventura, número 2 y en la medianera, conocida como Casa de Yanguas, del barrio del Albayzin de Granada ${ }^{1}$.

Durante varias visitas a la primera de estas dos casas y conforme se desarrollaban los trabajos de limpieza de los distintos paramentos, documentamos mediante dibujo y fotografía, los variados motivos que iban apareciendo.

Una vez localizados los grafitos, procedimos a delimitar el espacio que ocupaban en el muro, limpiar los enlucidos sobre los que se habían trazado, tomar las medidas necesarias de ubicación y confeccionar fichas de catalogación. A continuación, utilizamos una luz artificial rasante para detectar mejor el trazo de los motivos incisos. Posteriormente, llevamos a cabo el calco directo tanto de los trazos incisos como de los pintados, mediante película plástica transparente y rotuladores de tinta permanente.

Tras el trabajo de campo descrito, nuestra labor continuó con la reproducción a tinta sobre papel vegetal de los calcos realizados. Para ello, nos ayudamos de las fotografías tomadas tanto de conjunto como de detalle.

Aunque estamos desarrollando actualmente estudios más detallados de cada grafito o de grupos de ellos con temática similar, que se publicarán en próximos trabajos, recogemos en estas breves líneas los primeros resultados obtenidos, resal-

\footnotetext{
${ }^{1}$ Agradezco al Dr. Julio Navarro Palazón (LAAC Escuela de Estudios Árabes de Granada - CSIC), la oportunidad que me ha brindado de poder estudiar estos motivos.
}

tando la temática que presentan y ofreciendo una aproximación cronológica.

A partir de aquí, utilizaremos tanto en el texto como en los pies de figuras y láminas, las siglas C/SB para hacer referencia a la casa de C/ San Buenaventura, 2.

\section{LA CASA Y LOS GRAFITOS}

El estudio de las estructuras conservadas, nos revelan que se trata de una casa nazarí cuya crujía norte estaba compuesta originariamente de planta baja, planta alta y pórtico. En época morisca y principalmente en época barroca, esta estructura sufre una clara modificación: la doble elevación originaria se divide con una entreplanta, dando lugar a dos plantas superpuestas de baja altura. Es en esa referida entreplanta y en la superior donde se han descubierto los grafitos que más adelante estudiaremos.

La entreplanta actual esta ocupada por una única sala rectangular con unas dimensiones aproximadas de $7 \mathrm{~m} . \times 2,80 \mathrm{~m}$. En su muro oeste se abre una ventana hacia la calle y en el extremo oriental del muro sur de la estancia, se sitúa la puerta de acceso a la sala así como un pequeño ventanuco.

Tras levantar los modernos enlucidos que cubrían la cara interna del muro sur de la sala, se descubrió embutido a todo lo largo del muro y a una altura aproximada de $0,75 \mathrm{~m}$. del actual nivel del suelo, los restos del estribo de madera perteneciente a la armadura del primitivo salón nazarí, mantenido en época morisca y desmontado ya en época barroca. Por encima de esta línea se aprecia un recrecido del muro de aproximadamente un metro, realizado en época morisca, así como otros más modernos que soportan el envigado actual de la planta superior. 
Los motivos descubiertos en esta sala (Paneles 1-C/SB y 2-C/SB), se localizaron en antiguos enlucidos de yeso situados en la superficie que se extiende entre el estribo de madera y la actual solería de barro.

La planta superior es de dimensiones similares a la anterior, aunque el muro oeste de la estancia ha desaparecido completamente por desplome. En el extremo occidental del muro sur de la estancia, se sitúan una pequeña ventana así como la puerta de acceso a la sala, a la cual se llega por medio de una galería volada de madera con balaustrada y pies derechos con zapatas de "pecho de paloma".

Los grafitos existentes en esta planta se localizaron en los siguientes lugares:

- en la fachada exterior del muro sur de la estancia, concretamente en el espacio ocupado por la galería de madera volada (Panel 3-C/SB);

- en la cara interna de ese mismo muro, a la derecha de la puerta conforme se accede al interior de la sala (Panel 4-C/SB);

- en la jamba oeste de la puerta de acceso a la referida sala (Fig. 7);

- y sobre los enlucidos que cubren la mitad occidental del muro norte (Panel 5C/SB y Panel 6-C/SB).

Los elementos que contienen los paneles referidos, quedan resumidos de la siguiente manera:

Panel 1-C/SB (Fig. 1): Forman este panel tres barcos incisos en el enlucido. Uno de ellos prácticamente completo con personajes en su cubierta, y dos parcialmente conservados.

Panel 2-C/SB (Fig. 2): Ejecutados a compás se trazan varios círculos concéntri$\cos$ y una roseta hexapétala inscrita en un doble círculo. Entre una gran cantidad de líneas incisas de difícil lectura, vemos una " $b$ " minúscula de apariencia gótica.

Panel 3-C/SB (Fig. 3): Localizamos incisos, una roseta de cuatro pétalos, una figura que parece ser un ave, una estrella de cinco puntas, granadas aisladas y dos motivos que representan un corazón atravesado por una flecha, en cuyo interior se traza una "S" y una granada.

Panel 4-C/SB (Fig. 4): Un barco, dos personajes y una inscripción en caracteres latinos, aparecen dibujados a carboncillo, así como un "elemento de cuenta" y otros tres barcos, mediante la técnica de la incisión.

Panel 5-C/SB (Fig. 5): Se trata del panel más grande de esta casa, siendo los "elementos de cuenta", los motivos más reiterados. Se pueden ver además, dos cruciformes sobre peana, círculos a compás, un barco, algunas letras mayúsculas y números. Todos estos motivos aparecen incisos en el enlucido.

Por último, el Panel 6-C/SB (Fig.6): Contiene un antropomorfo junto a un sencillo motivo heráldico, así como varios mástiles con cuerdas y vela cuadra.

\section{TEMATICA E INTERPRETACION DE LOS GRAFITOS}

En este apartado hemos agrupado los grafitos aparecidos en los distintos paneles, en base a la temática que ofrecen. Así pues, las categorías temáticas que hemos creado han sido las siguientes: Barcos y motivos navales, figuras humanas, zoomorfos, motivos vegetales, elementos de cuenta, motivos simbólico-geométricos (corazones, estrellas, rosetas, cruces) e inscripciones.

Sin más dilación procederemos a continuación a comentar de manera más detallada cada categoría.

Barcos y motivos navales 
Es uno de los grupos temáticos más numeroso. Contamos con nueve ejemplares bien definidos, ocho trazados mediante la técnica de la incisión y uno pintado a carboncillo. Todos los incisos se distribuyen en los distintos muros de las dos plantas, y el realizado a carboncillo se descubrió en la planta superior de la casa.

El grupo de barcos y motivos navales incisos (completos y parcialmente conservados) (Figs. 1, 4, 5, 6 y Foto.1) que hemos localizado en ambas plantas de la casa, muestran un modelo de nave que ofrece un arrufo de la quilla muy pronunciado, casi semiesférico, con portas de los cañones en el primer nivel de tablazón. Tienen tres palos (o más) con cofas y flechastes entre los obenques que forman escalas. Las velas aparecen aferradas y se pueden ver banderas y gallardetes en los mástiles. Son interesantes los estandartes que ondean en la embarcación del Panel 5-C/SB, ya que no se trata de simples banderas rectangulares de rápido y fácil trazado como habitualmente se representan en grafitos de embarcaciones o castillos, sino que son varias líneas horizontales que nacen del mástil. Algunos estandartes similares los podemos ver en los grafitos de embarcaciones, del siglo XVIII, descubiertos en la Casa del Gobernador de la Isla de Tabarca (Alicante) ${ }^{2}$. En la proa parece distinguirse un castillete $y$ resulta interesante la aparición en cubierta de personajes que constituyen la tripulación de la embarcación.

El barco realizado a carboncillo, situado en la planta superior de la casa (Fig. 4 y Foto 3), está más elaborado que los anteriores descritos. Mantiene igualmente una quilla semiesférica muy exagerada, esta vez con doble fila de batería, donde se pueden

\footnotetext{
${ }^{2}$ P. Bevia, R. Peñalver, P. Ferre, J. Ma. Ferrandiz Y Ma. F. MARTín, "Avance del corpus de graffiti del término municipal de Alicante", LQNT, 1, 1993, pp.185-190, en especial p.190.
}

observar las portas con los falconetes a la vista. Tiene los tres palos como cogidos en racimo en la cofa, a modo de tridente. Se observan los flechastes entre los obenques formando escalas. Esta nave presenta una doble perspectiva, donde el casco se presenta de perfil mientras que la popa y los palos se muestran de frente. El castillete de popa, que esta rematado por almenas triangulares, se corona por un gran fanal sobre el que se dispone una cruz. El espejo de popa aparece decorado con un escudo coronado y en la proa se puede ver un gran mascarón, de tema oriental, que parece representar la cabeza de un turco o berberisco. Por último, del gran botalón que culmina en una cruz, ondea una enorme bandera decorada con otra cruz inscrita en un círculo, tal y como se repite en el palo mayor de la nave.

La similar arquitectura que presentan ambos modelos de barcos, nos hace pensar que son obra de un mismo autor, que primero dibuja y después lo intenta con la técnica de la incisión, con menos éxito. Pero cabe también la posibilidad de que los barcos incisos sean de otro autor, que copia el pintado en negro por mimetismo, en un momento posterior no muy lejano, quedando algunas líneas incisas superpuestas al motivo dibujado.

Creemos que nuestros barcos, tanto los incisos como el pintado a carboncillo, representan naves de combate, de la clase de los galeones de los siglos XVII-XVIII, y que a pesar de la estilización y simpleza ofrecida por los primeros, la ornamentación que porta el segundo es claramente barro$\mathrm{ca}^{3}$.

Grafitos de embarcaciones con diseños parecidos se localizan en Mallorca, en

\footnotetext{
${ }^{3}$ Agradezco a la Dra. Elvira González Gozalo, las generosas opiniones que me ha brindado sobre algunos aspectos de los barcos que presento.
} 
el fortín de Cala Llonga (Cala d'Or, en Santanyí $)^{4}$ y en la Iglesia de San Francisco de Palma ; en Alicante, en el Castillo de Santa Bárbara, Casa Capiscol y en la Casa del Gobernador de la Isla de Tabarca ${ }^{6}$; y por último en Zaragoza, en el Salón del Trono de la Aljafería ${ }^{7}$.

La posibilidad de que fuese una misma persona la autora de los distintos barcos, y el gran número que hay, nos hace pensar que tal vez, quien habitó la vivienda fuera un marino o se dedicara a actividades relacionadas con el mar. Sea como fuere, resulta extraño localizar este tipo de motivos en una casa tan alejada de la costa.

\section{Figuras humanas}

En la entreplanta de la casa contamos con los tres personajes, antes referidos, que conforman la tripulación de dos de los tres barcos incisos (Fig. 1). Apenas nos aportan información, tan sólo resaltar que el personaje situado bajo la cofa del palo mayor, con los brazos levantados por encima de la cabeza, parece que sostuviera lo que podríamos interpretar con algún tipo de aparejo (cuerdas, redes...). La aparición de

-

${ }^{4}$ E. GonzÁlez Gozalo, “Tipos náuticos en los graffiti mallorquines (siglos XIV- XIX)", Actes du IXe Colloque International de Glyptographie d'Hoepertingen (Euregio) 1992, CIRG, Braine-le-Château, 1993, pp. 255271, lám.51, fig.1. BCL.

${ }^{5}$ E. GONZÁlez GOZALO, "Los graffiti de la iglesia de San Francisco de Palma: los ingenios del ocio", Bolletí de la Societat Arqueológica Luliana, 49, 1993, pp.151-179, lám. IV.

${ }^{6}$ R. Peñalver López y J. Ma. Ferrándiz Ruíz, "Avance al estudio de los motivos navales del corpus de grafitos del término municipal de Alicante", I Congrés Internacional de Gravats Rupestres $i$ Murals, Lleida 1992, 2003, pp.847-860; P. ROSSER LIMIÑANA, "Los graffiti de los siglos XVII-XVIII descubiertos en la Casa Capiscol (La Condomina, Alicante)", LQNT, 2, 1994, pp.225-234.

7 J. I. ROYO GUILLÉN, Y F. GÓMEZ LECUMBERRI, “Panorama general de los "graffiti" murales y de los grabados al aire libre medievales y post-medievales en Aragón", Al-Qannis, 9, 2002, pp.55-156, en especial pp.73-75. estos personajes en la cubierta de la embarcación, bastante excepcional en este tipo de representaciones, le otorga al Panel 1-C/SB, cierto aire naturalista y quizás narrativo. Se trataría de la plasmación gráfica de una escena, que tal vez acompañara a un relato oral en el momento de su ejecución.

Localizamos también junto al barco pintado a carboncillo anteriormente descrito, y mediante la misma técnica de ejecución, los rostros de un hombre y una mujer a modo de auténticos retratos o pequeñas estampas enmarcadas, de claro sabor barroco (Fig. 4 y Foto 4). De la mujer tan sólo se conserva un leve esbozo de su silueta, donde podemos entrever el amplio peinado de su cabeza. En cambio el hombre se conserva bastante bien. Parece llevar traje con alta solapa vuelta, posiblemente una casaca, y pañuelo en torno al cuello, peluca o peinado con raya al medio y bucles o rizos a los lados de la cara.

Por último, en el muro norte de esta misma sala (Panel 6-C/SB), vemos un motivo antropomorfo realizado mediante pequeñas líneas incisas que se entrecruzan, junto a lo que podríamos interpretar como un sencillo motivo heráldico (Fig. 6).

\section{Zoomorfo}

En la planta superior de la casa, podemos ver en la fachada exterior del muro sur, donde se sitúa la galería volada de madera, un grafito inciso que representa un ave zancuda de pico largo, que pudiera tratarse de una cigüeña.

\section{Motivos vegetales}

Localizamos cuatro grafitos incisos que representan granadas (Fig.3). Se sitúan en la planta superior, concretamente, en el espacio ocupado por la galería de madera volada. Una de estas granada aparece parcialmente conservada, otra la localizamos aislada y dos más aparecen en el interior de corazones. 
A media altura de la jamba oeste de la puerta de acceso a la estancia que ocupa esta planta superior, podemos ver pintada a carboncillo y en almagra, una granada bajo una corona, rematada a su vez por una pequeña cruz (Fig.7). Está dibujada muy al estilo de las granadas que decoran la cacharrería y placas de nombres de calles, del siglo XVIII, de la típica cerámica granadina de Fajalauza ${ }^{8}$.

En esta misma estancia ya vimos anteriormente la existencia de grafitos pintados a carboncillo que representaban pequeños retratos enmarcados de un hombre y una mujer. Los marcos que rodean esos personajes, aparecen decorados con motivos vegetales en forma de trébol (Fig. 4).

\section{Elementos de cuenta}

Estos grafitos consisten en agrupaciones de líneas verticales consecutivas, trazadas en algunas ocasiones bajo una línea horizontal y la mayoría de las veces atravesadas por ella.

Hemos de interpretarlos como simples anotaciones, que quizás respondan a una forma arcaica de contar.

Es común que estas líneas aparezcan en recintos carcelarios, como los del Castillo de Petrer (Alicante), en los campanarios de la Catedral y de la Iglesia de San Miguel de Mallorca, así como en la Torre del Homenaje del Castillo de Bellver (Mallorca), en las cárceles de La Fresneda y Mazaleón (Teruel), o los que hemos descubierto en la Torre del Homenaje de la Alhambra (actualmente en fase de estudio), utilizada como prisión durante los siglos XVIII-XIX, y cuya función era el cómputo del tiempo de reclusión del cautivo, autor del grafito.

8 J. L. Garzón CARdenete, Cerámica de Fajalauza, Granada, 2004, pp.143-144; C. CANO PIEDRA Y J. L. GARZÓN CARDENETE, La cerámica en Granada, Granada, 2004.
También aparecen junto a molinos, haciendo referencia al tiempo o turno de molienda, o en zonas de almacenaje aluden al número de productos acumulados.

Este tipo de grafitos los encontramos, de manera incisa y muy numerosos, en los enlucidos que cubren el muro norte de la estancia superior de la casa (Fig. 5).

Sobre nuestros motivos, decir tan sólo, que no sabemos que contabilizaban realmente. Tal vez, hagan alusión a productos almacenados o elaborados en este espacio, relacionados quizás de una forma $u$ otra con el mundo marinero, dado que en la misma estancia, así como en la inferior, se descubrieron numerosos grafitos que representan motivos navales, como ya hemos referido. Además, hay que tener en cuenta que a mediados del siglo XVIII se produce en la Vega de Granada la "Primera Revolución Agrícola", con la implantación de nuevos cultivos de carácter industrial, como el lino, que triplicaría su extensión, o el cáñamo, que la multiplicaría por seis, llegando a ocupar más de una cuarta parte de las tierras irrigadas. La rápida expansión de estos cultivos, vino asociada a la demanda de velámenes y cordelería de la Marina, ya que los aparejos de los buques del Dieciocho y el Diecinueve, llamados "bosques flotantes", se convirtieron en verdaderos devoradores de miles de toneladas de fibras vegetales. Como recuerdo de ese auge industrial, hemos de fijarnos en el callejero granadino, con nombres como la Calle Lineros o la Placeta del Lino (donde estuvo su aduana), y en el mismo barrio del Albayzín, el Carril de la Lona y la Casa de la Lona, por la fabricación de velas para barcos.

\section{Motivos simbólico-geométricos}

En esta categoría incluimos grafitos que representan motivos claramente simbólicos, como son corazones, estrellas y cruces, así como otros que aunque también reúnen ese mismo carácter simbólico, fue- 
ron trazados utilizando el compás, dando lugar a complejos motivos geométricos. Hablamos de rosetas hexapétalas inscritas en círculos.

Dos corazones incisos en el enlucido, atravesados por una flecha y en cuyo interior aparecen la letra "S" y una granada, tal como ya vimos al hablar de los motivos vegetales, se sitúan en la fachada que soporta la galería volada de madera en la estancia superior de la casa (Fig. 3 y Foto 5).

El corazón es un motivo clásico de la iconografía barroca. Aparecen corazones flameantes, radiantes, atravesados por flechas, con espinas o del que nace una $\mathrm{cruz}^{9}$. La mayoría de ellos responden al símbolo cristiano del Sagrado Corazón de Jesús. Nuestros grafitos recuerdan a esos motivos, aunque podrían también hacer alusión al amor que se siente por alguien o algo ${ }^{10}$. Motivos iguales al nuestro han sido localizados en Mallorca, en contextos de los siglos XVII a XIX.

Una gran estrella de cinco puntas aparece incisa sobre los corazones y granadas antes descritas, que encerraría posiblemente poderes profilácticos y mágicos.

También hallamos junto a los corazones y la estrella referidos, una gran roseta inscrita en un círculo. Otra de tamaño más pequeño, se localiza en la estancia que ocupa la entreplanta de la vivienda, por debajo

${ }^{9}$ E. GONZÁLEZ GOZALO, “Los graffiti de la iglesia de San Francisco de Palma...", lám. II-2, IX-1 y IX-5; J. I. ROYO GUILLÉN, Y F. GÓMEZ LECUMBERRI, “Panorama general de los "graffiti" murales y de los grabados al aire libre...", p.122, fig. 54; E. GONZÁLEZ GOZALO Y M. ROSELló PONS, Los grafitos de la Torre del Homenaje del Castillo de Bellver, Palma de Mallorca, 2006, núm. 62 del catálogo.

${ }^{10}$ M. BERnAT, E. GONZÁlez Y J. SERRA, "Els graffiti del campanar de la Seu de Mallorca", Estudis Baleárics, 23, IV, 1986, pp.7-46, fig.19 del inventario; E. GONZÁLEZ GOZALO, "Los graffiti de la iglesia de San Francisco de Palma...", lám. VII-3. del estribo de madera conservado en el muro (Fig. 2 y Foto 2).

Al igual que la estrella referida, estas rosetas podrían ser signos mágicos de carácter profiláctico, pero también pruebas o bocetos de diseños decorativos, tal vez para aplicar en algún zócalo, de características similares al dado a conocer por Emilio de Santiago Simón ${ }^{11}$, procedente de una casa morisca cercana a la nuestra, y a las que hemos descubierto en otra casa morisca de la Calle San Martín, 16, actualmente en fase de estudio.

Grafitos con rosetas se documentan en contextos cristianos, como el Monasterio de San Millán de Suso (La Rioja) ${ }^{12}$, la Lonja de Palma de Mallorca ${ }^{13}$ y el Castillo de Petrer (Petrer, Alicante) ${ }^{14}$. Las existentes (como bajorrelieves) en la iglesia prerrománica de Santa María de Quintanilla de las Viñas (Burgos), han sido interpretadas de la siguiente manera: "Estas flores son frecuentemente símbolo de Cristo, árbol de la vida, y a menudo ocupan el centro de las cruces anicónicas, como flores del árbol de la vida. A veces aparecen combinadas con la estrella de David, los dos triángulos enlazados. De la misma forma que estas flores se representan las estrellas en los códices mozárabes, aunque generalmente de ocho puntas. En Ap. 22,16 dice Cristo: «Yo soy

${ }^{11}$ E. De SAntiago Simon, "Restos de un zócalo morisco en una casa del Albaicín", Miscelánea de estudios Árabes y Hebraicos, XXIII, Fasc. 1ํ, 1974, pp.121-123.

12 M. IBÁÑEZ RODRÍGUEZ Y T. LEJÁRRAGA NIETO, Los grafitos del Monasterio de San Millán de Suso, Logroño, 1998, ver las figuras IV-13.1, IV-13.2, IV-66 y V-10.

${ }^{13}$ E. Gonzalez GozalO, "Graffiti a la Torre de Sant Joan de la Llotja", Bolletí del Institut d'Estudis Baleàrics, IV, 23, 1986, pp.47-56, fig.16; E. GoNZALEZ GozAlO, "Los graffiti de la Lonja de Palma de Mallorca (España) (2)", Actes du VIIlème Colloque Internacional de Glyptographie du Rochefort-Sur-Mer, 1990, pp.123-133, en especial p.131.

${ }^{14}$ C. NAVARRO POVEDA, Graffitis y signos lapidarios del Castillo de la Mola (Novelda) y del Castillo de Petrer, Petrer (Alicante), 1993, pp.99-100. 
la raíz y el linaje de David, la estrella brillante de la mañana»"15.

Pero esta iconografía no es exclusiva del mundo cristiano, dado que se remonta a la Edad del Bronce, y se interpretan como símbolos solares de carácter protector, reconociéndose también en ambientes funerarios (principalmente en estelas) e incluso se detecta su presencia en el mundo islámi$\mathrm{Co}^{16}$.

Dos pequeñas cruces latinas sobre peanas ligeramente triangulares, podemos verlas incisas junto a los elementos de cuenta, en la estancia superior de la casa (Fig.5). El brazo vertical de estas cruces se prolonga hacia abajo dividiendo en dos las peanas.

Aparte de estos motivos cruciformes, contamos con otros asociados a distintos elementos: una cruz remata la granada coronada pintada en la jamba de la puerta de acceso a la estancia superior de la casa y en la embarcación pintada a carboncillo, se pueden ver cruces en los estandartes, coronando el fanal, el botalón y en el palo mayor.

\section{Inscripciones}

Tan sólo contamos con una inscripción, también a carboncillo, junto al personaje masculino y el barco situado en la planta superior de la vivienda, que podemos transcribir como "Señor mio" (Fig.4).

\footnotetext{
${ }^{15}$ Ma. A. SEPÚLVEDA GONZÁLEZ, “Los anagramas y el programa iconográfico de Quintanilla de las Viñas: una hipótesis de interpretación", En la España Medieval, V, 1986, pp.1217-1248, en especial p.1230.

${ }^{16} \mathrm{~J}$. A. SOUTO LASALA, "Marcas de cantero, graffiti y signos mágicos en el mundo islámico: panorámica general", Actas del V Coloquio Internacional de Gliptografia, Pontevedra, 1986, pp. 463-486.; F. VALDÉS FERNÁNDEZ, "Relieves musulmanes de carácter profiláctico en la fortaleza de Górmaz (Soria)", XIV Congreso Nacional de Arqueología (Vitoria 1975), Zaragoza, 1977, pp.12751278.
}

También debemos de incluir en este apartado la " $b$ " minúscula de apariencia gótica situada en el panel 2-C/SB (Fig.2), las letras mayúsculas $\mathrm{B}$ y $\mathrm{A}$ del panel $5-\mathrm{C} / \mathrm{SB}$, así como los números 1, 2, 4 ó 9 de ese último panel (Fig.5).

\section{CONCLUSION}

Valgan las siguientes líneas, como primeros resultados no concluyentes, de los distintos motivos descubiertos, ya que estamos realizando actualmente estudios más detenidos de ellos, que serán dados a conocer en próximos trabajos.

Los grafitos descubiertos en la casa de C/ San Buenaventura, 2 podemos situarlos en el siglo XVIII.

Ofrecen una iconografía característica de este periodo, donde aparecen cruces sobre peana, aves, corazones atravesados por flechas, granadas (una de ellas con corona)..., es decir, figuras todas ellas presentes en las decoraciones oficiales del barroco granadino, pudiéndolas encontrar también a nivel popular, en las cerámicas de Fajalauza del siglo XVIII.

Así mismo, la arquitectura barroca que ofrecen las embarcaciones, emparentada con la de los galeones, y en especial la ornamentación de la pintada a carboncillo, las sitúan igualmente en este siglo. No hay que olvidar tampoco la indumentaria y el peinado del hombre representado en el pequeño retrato situado junto a la embarcación anterior, posiblemente con casaca y peluca.

Si consultamos la abundante bibliografía sobre grafitos descubiertos que representan barcos, podemos ver como se han ofrecido distintas interpretaciones de los mismos, en función del lugar donde se han localizan:

- la aparición en lugares cercanos a la costa es bastante frecuente, mostrando bar- 
cos muy elaborados, posiblemente realizados por gentes que estaban acostumbrados a verlos diariamente, es el caso de los grafitos del Castillo de Denia ${ }^{17}$ o de distintos edificios de las Islas Baleares ${ }^{18}$;

- los existentes en recintos carcelarios, a veces dibujados con todo tipo de detalles, fueron ejecutados posiblemente por marinos cautivos, como por ejemplo los de la prisión de Castelló d'Empuries ${ }^{19}$;

- los de edificios sagrados, como la Iglesia de Santa Cruz y la Catedral de Palma $^{20}$, quizás se realizaron a modo de $e x$ votos, para agradecer a la divinidad el salvarse de los peligros del mar o de acontecimientos bélicos.

Nuestro caso resulta un tanto peculiar, ya que no responde a ninguna de las interpretaciones referidas y además los grafitos se encuentran situados en una casa muy alejada de la costa. Quizás, como ya hemos dicho a lo largo de estas líneas, habitara en nuestra vivienda algún marino o se destinaran estas estancias a almacenar o elaborar productos relacionados con el mundo marinero. Antes hemos aludido a la gran importancia de la implantación de nuevos cultivos de carácter industrial, como el lino y el cáñamo en la Vega de Granada, asociados a la gran demanda de velámenes y cordelería de la Marina, su

${ }^{17}$ A. BAZZANA, M. P. LAMBLIN, Y Y. MONTMESSIN, Los graffiti medievales del Castell de Denia. Catálogo, Denia (Alicante), 1984.

18 E. González Gozalo y B. Oliver Font, Los Barcos de Piedra. La arquitectura náutica balear a través de los grafitos murales (siglos XIV-XVIII), Illes Balears, 2007.

19 E. Carbonell, A. Casanovas, y C. Llaras, "Problemática de la interpretación de los graffiti medievales catalanes", I Congreso de Arqueología Medieval Española, Huesca 1985, t. I, Zaragoza, 1986, pp.257-271, en especial p.263.

${ }^{20}$ E. GonzÁlez Gozalo Y X. PAStor Quijada, "Arquitectura naval de los graffiti medievales mallorquines", IV Congreso de Arqueología Medieval Española, T. III, Alicante, 1993, pp.1035-1047, en especial p.1039. reflejo en el callejero granadino y en la denominación de algunos edificios.

Para terminar, decir tan sólo, que queda mucho camino por recorrer en el estudio de los grafitos históricos de Granada. La documentación de estos motivos solo será posible con la estrecha colaboración entre autoridades, profesionales de la Arqueología y Arquitectura y los que nos dedicamos al estudio de estas manifestaciones gliptográficas. De esta manera, podremos confeccionar un Corpus de motivos, que por sí mismo, constituirá un documento histórico de primera mano, que desvelará aspectos, a veces desconocidos, de la historia de nuestra ciudad y de los hombres que la habitaron ${ }^{21}$.

\footnotetext{
${ }^{21}$ Relacionamos los trabajos que hemos realizado o estamos desarrollando actualmente, sobre grafitos de época medieval y post-medieval: J. I. BARRERA MATURANA, "Graffiti en la muralla del Albayzín", Arqueología y Territorio Medieval, 9, 2002, pp.289-328; J. I. BARRERA MATURANA, "Los graffiti de la muralla islámica de Granada", I Congrés Internacional de Gravats Rupestres i Murals, Lleida 1992, 2003, pp.721-733; J. I. BARRERA MATURANA, "Participación de cautivos cristianos en la construcción de la muralla nazarí del Albayzín (Granada): sus graffiti", Arqueología y Territorio Medieval, 11.1, 2004, pp.125-158; J. I. BARRERA MATURANA, "«Trazados de edificios moros»: graffiti medievales en los subterráneos de la Torre de Comares de La Alhambra", Arqueología y Territorio Medieval, 13.1, 2006, pp.197-217; J. I. BARRERA MATURANA, “Representación de una mujer morisca en un graffiti del Albayzín (Granada)", Anaquel de Estudios Árabes, 18, 2007, pp.6591; J. I. BARRERA MATURANA, "Grafitos medievales en Granada", Arqueología, Historia y Viajes sobre el Mundo Medieval, EDM Revistas, 22, 2008, pp.30-39; J. I. BARRERA MATURANA, "Grafitos históricos en la casa morisca de Calle San Martín, 16 (Granada)", Arqueología y Territorio Medieval, (en prensa); J. I. BARRERA MATURANA, "Nuevos graffiti en Madinat al-Zahra", Cuadernos de Madinat al-Zahra, (en prensa); J. I. BARRERA MATURANA, "Grabados parietales y rupestres de Almería: Un problema de cronología", I Congrés Internacional de Gravats Rupestres i Murals, Lleida 1992, 2003, pp.709720; J. I. BARRERA Maturana, P. CRESSIER y J. A. MOliNA MUÑOZ, "Garabatos de alarifes: Los graffiti de las galerías de desagüe de Madinat al-Zahra", Cuadernos de Madinat al-Zahra, 4, 1999, pp.39-81.
} 


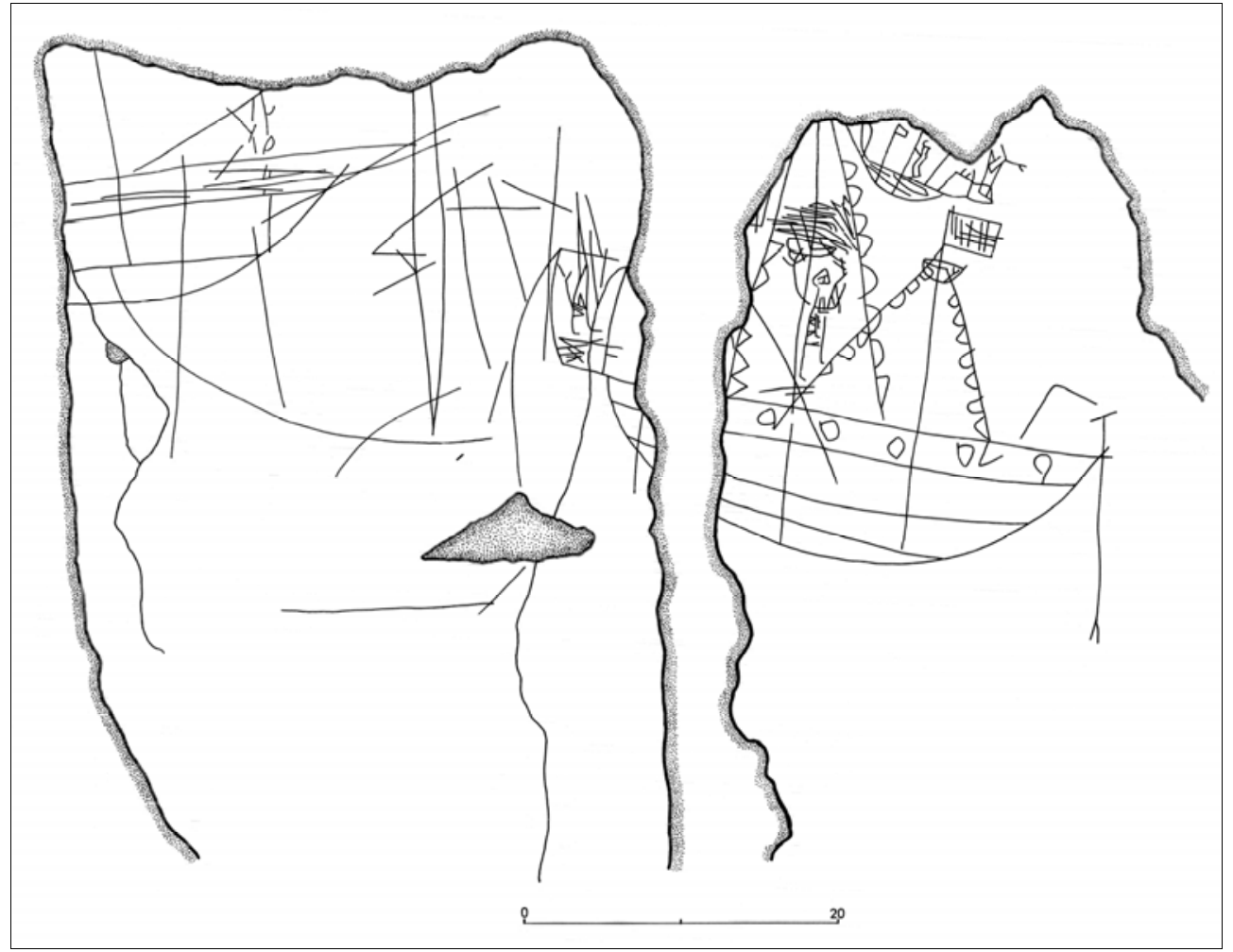

- Fig. 1. Panel 1-C/SB: Barcos con personajes en la cubierta.

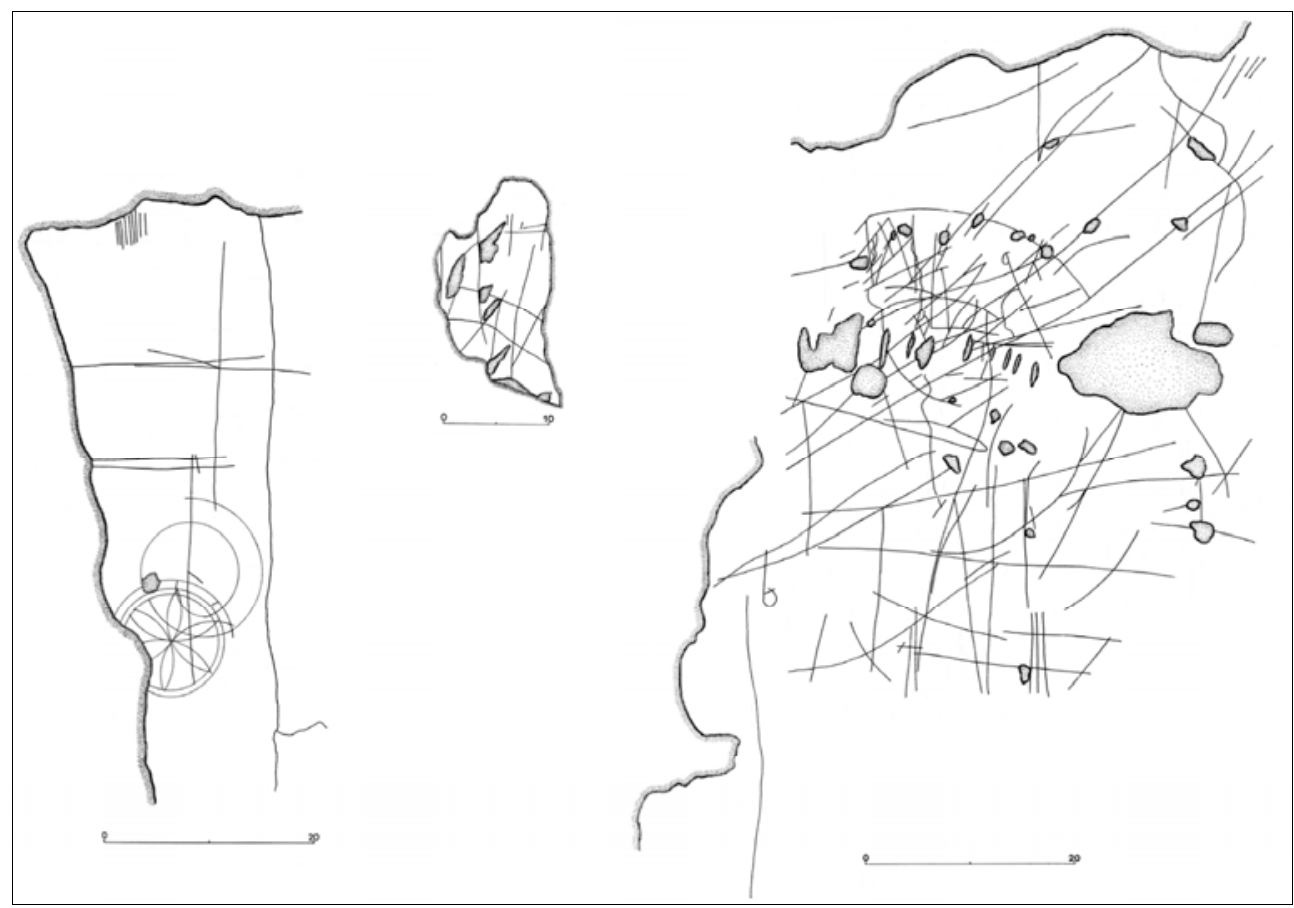

- Fig. 2. Panel 2-C/SB: Roseta hexapétala y letra " $b$ ". 


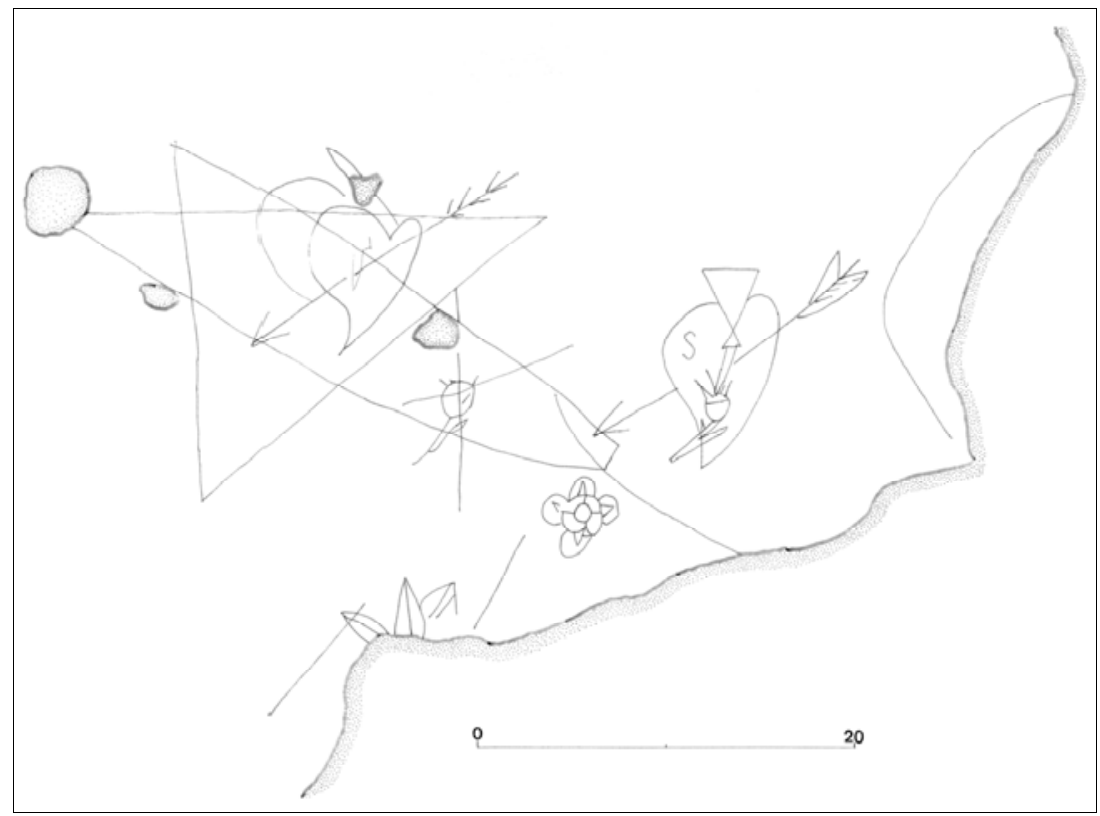

- Fig. 3. Panel 3-C/SB: Estrella, Corazones y granadas.

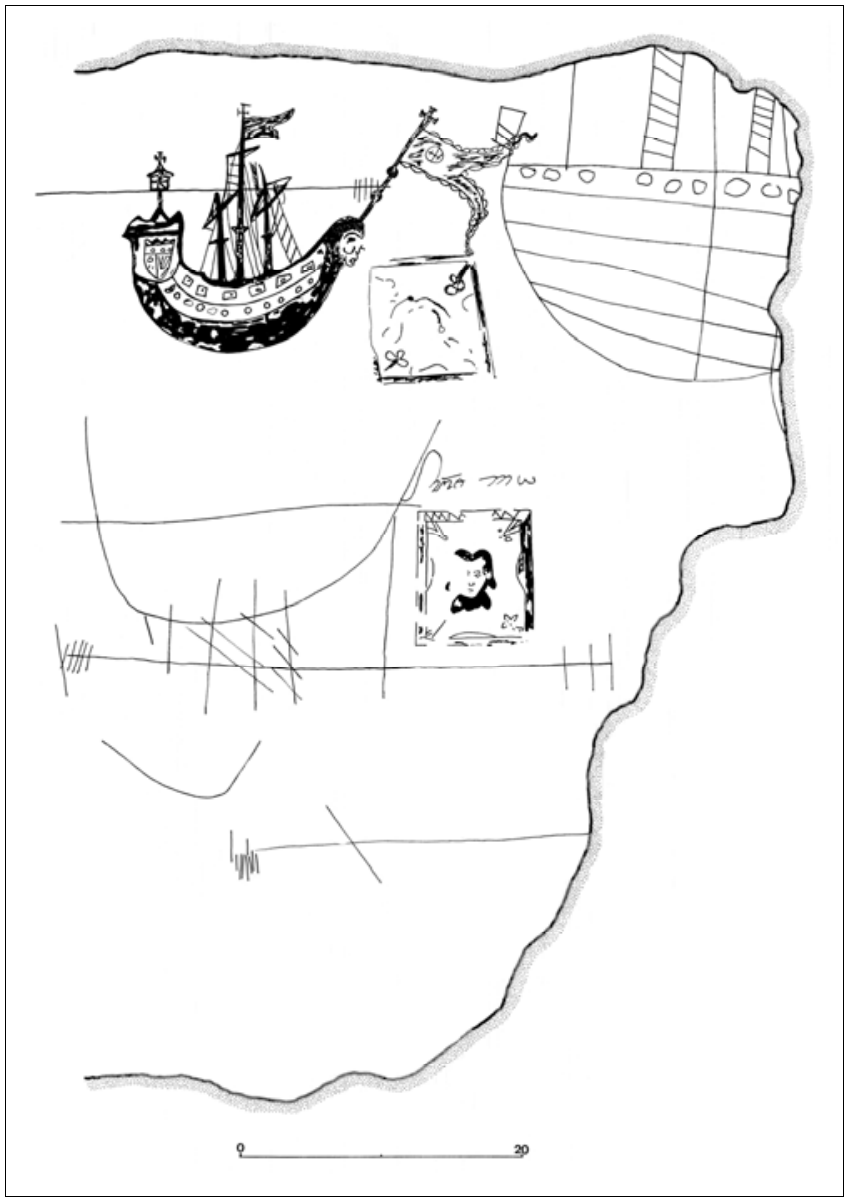

- Fig. 4. Panel 4-C/SB: Barcos, elementos de cuenta, personajes e inscripción. 


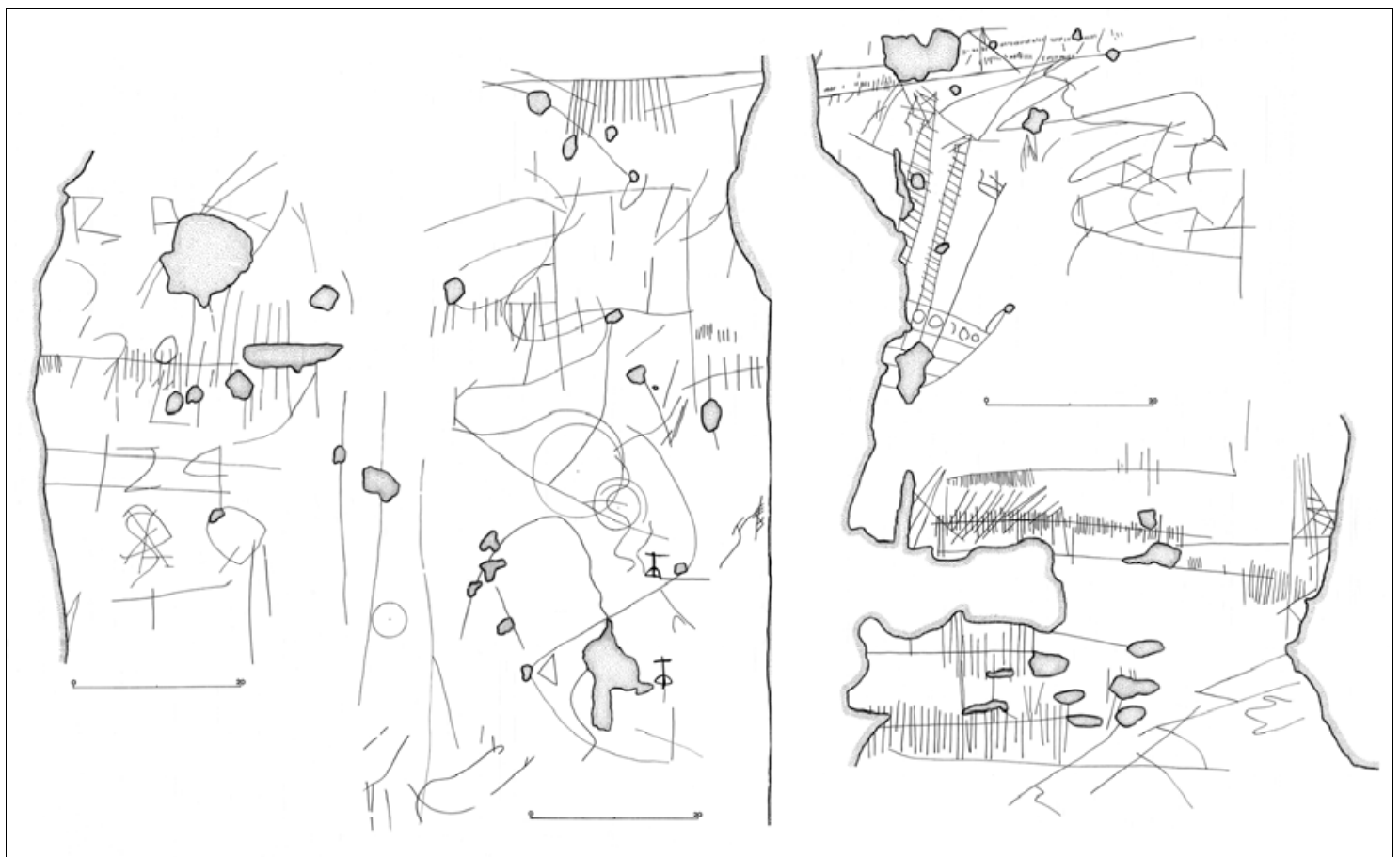

- Fig. 5. Panel 5-C/SB: Elementos de cuenta, barco, cruces, círculos, letras y números.

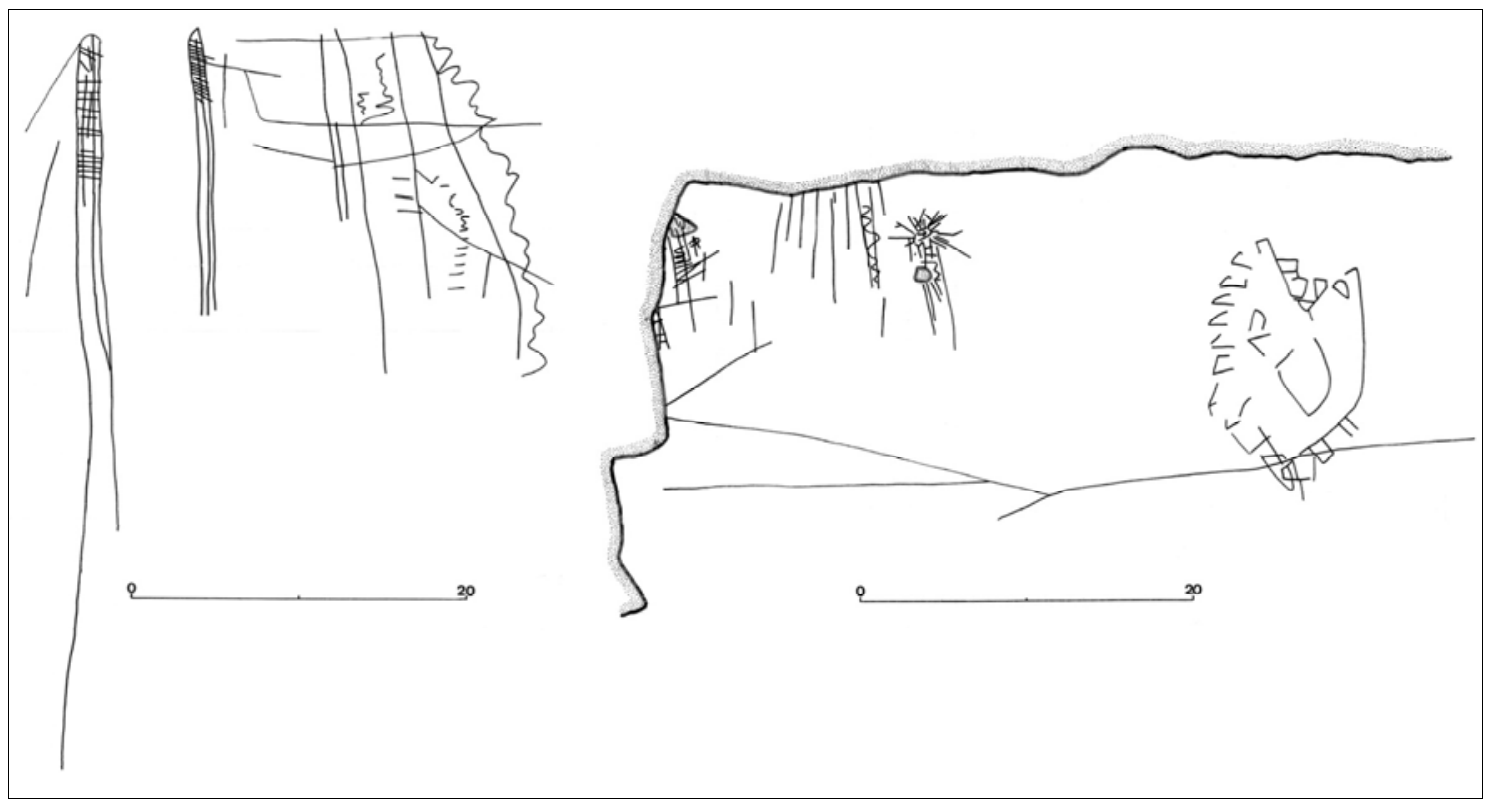

- Fig. 6. Panel 6-C/SB: Mástiles con cuerdas y vela cuadra, antropomorfo y escudo.. 


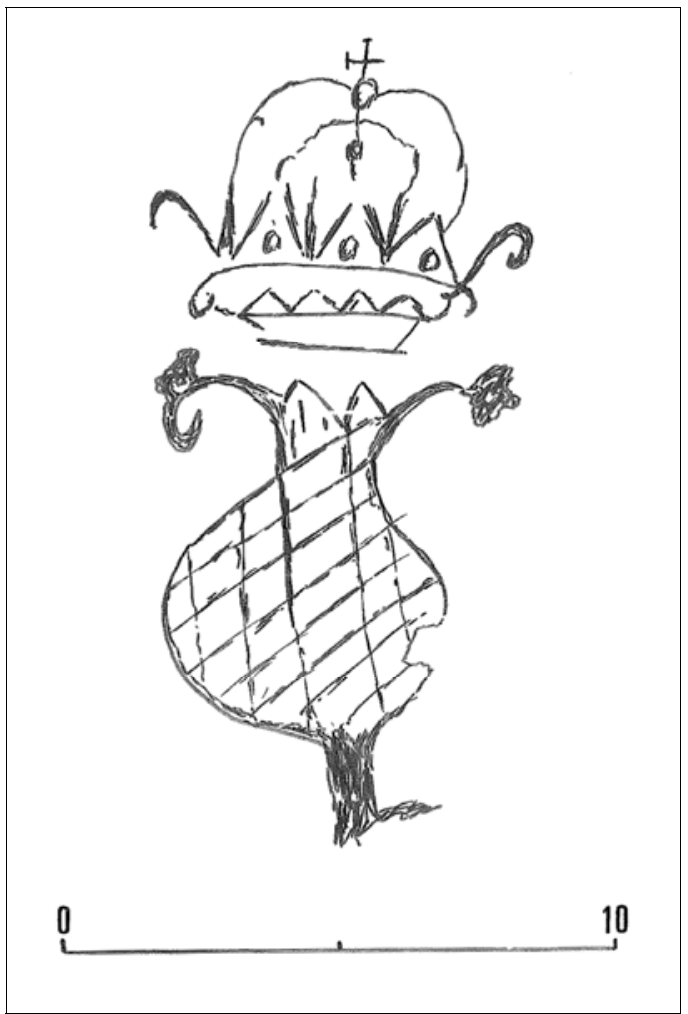

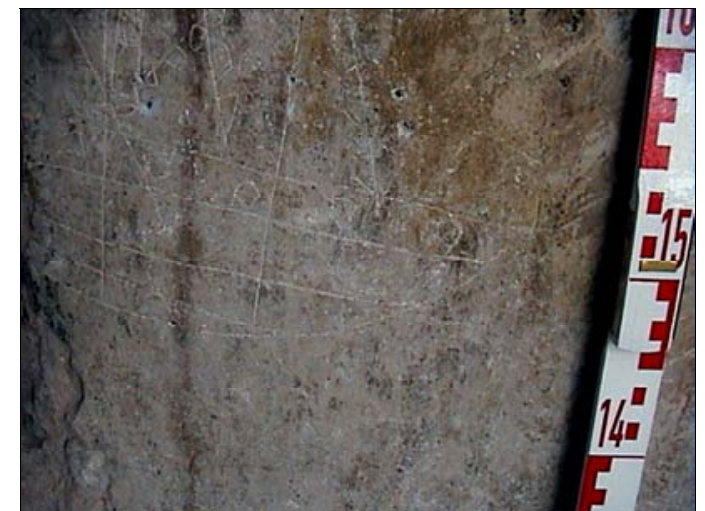

- Foto. 1. Barco de la figura 1.

- Fig. 7. Granada coronada dibujada a carboncillo.

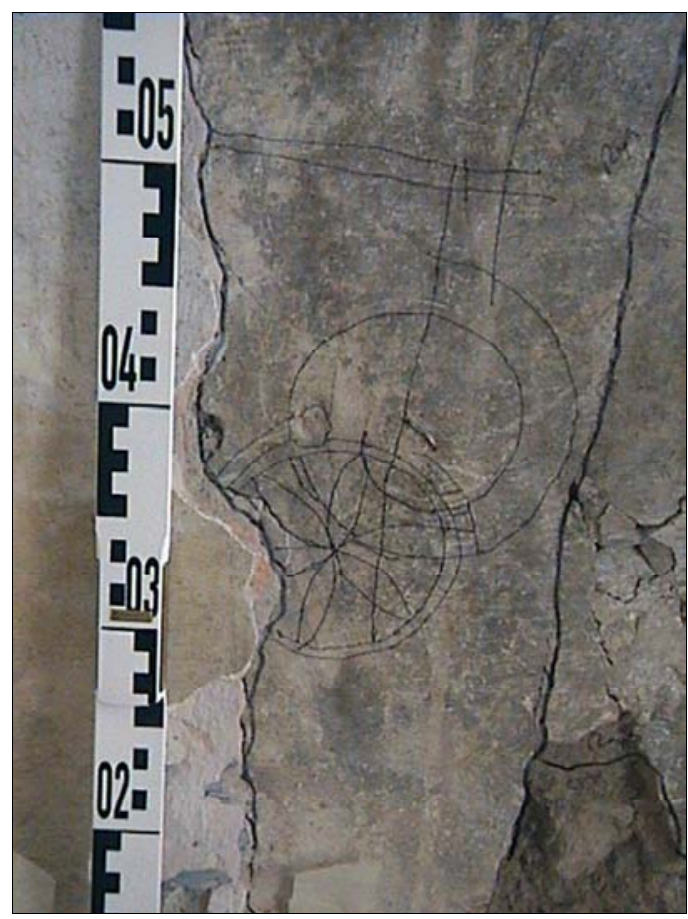

- Foto. 2. Roseta de la figura 2 durante el proceso de calco.. 


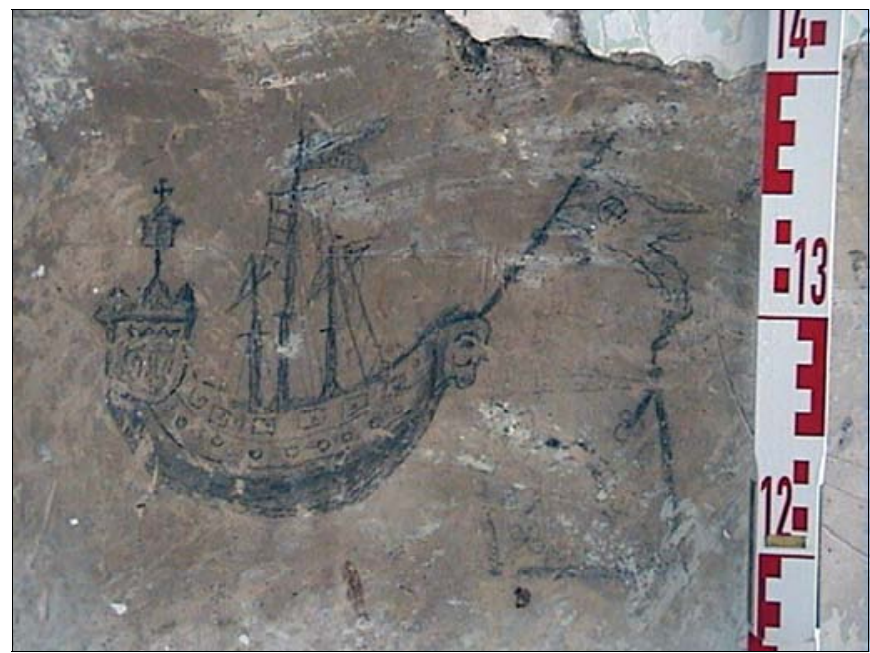

- Foto. 3. Barco dibujado a carboncillo de la figura 4.

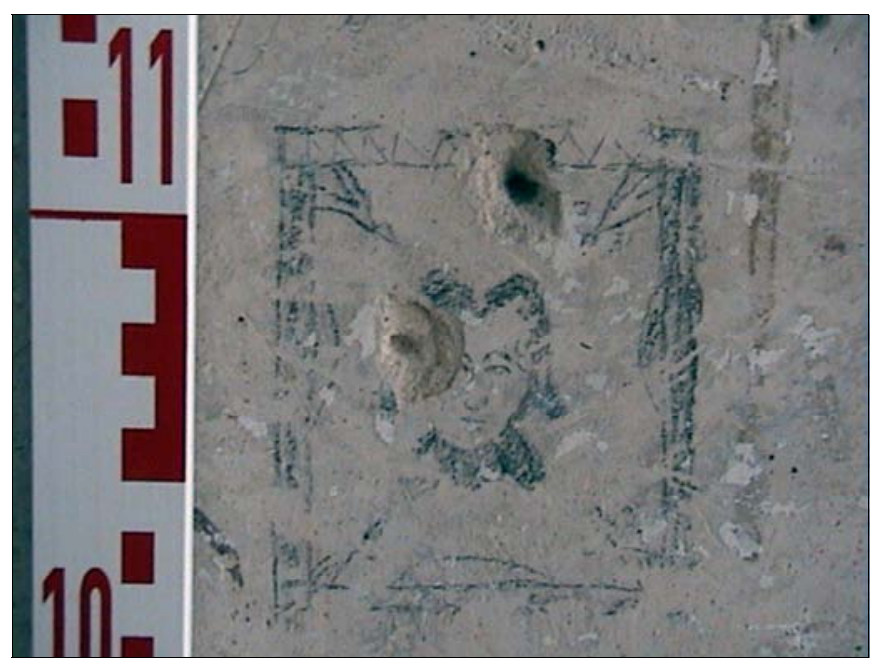

- Foto. 4. Personaje dibujado a carboncillo de la figura 4.

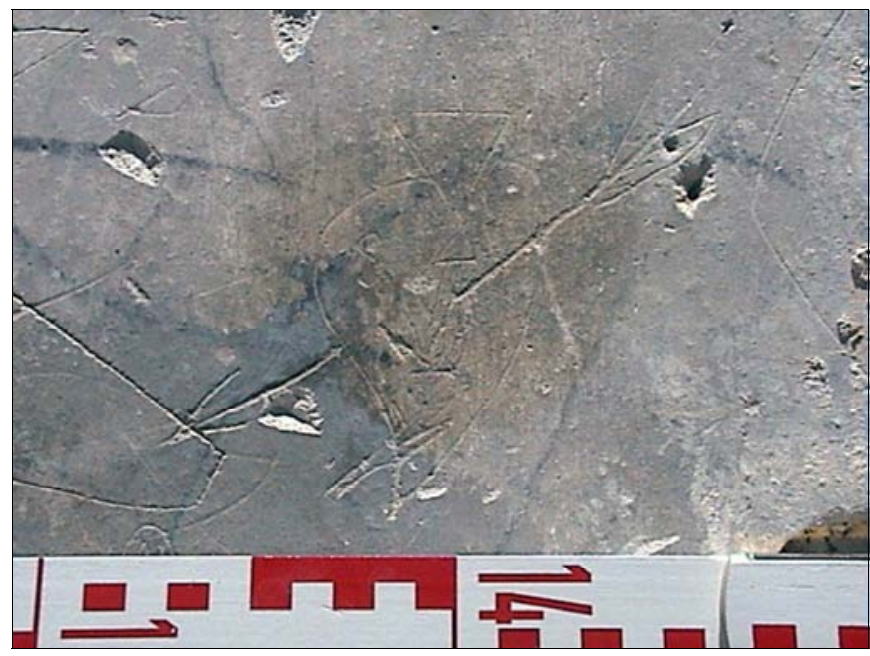

- Foto. 5. Corazón atravesado por una flecha, con granada y letra "s" en su interior de la figura 3. 